\title{
Sentidos da necessidade em Leibniz
}

$M$ arta de $M$ endonça

Faculdade de Ciências Sociais e Humanas da Universidade Nova de Lisboa

resumo Leibniz defende que há formas de necessidade compatíveis com a moralidade e outras que o não são. Para dar razão desta afirmação analisam-se diversas classificações da necessidade apresentadas por Leibniz, procurando salientar a sua irredutibilidade. Este facto permite pensar que a doutrina da necessidade de Leibniz não pode ser reduzida a um único plano de análise, seja ele lógico ou metafísico, mas deve ter em conta simultaneamente diversos planos de análise.

palavras-chave necessidade - Leibniz - modalidades - determinismo - contingência liberdade

\section{A necessidade: entre a ambiguidade e a univocidade}

a) 0 risco de equívoco

0 conceito de necessidade não é no pensamento de Leibniz um conceito unívoco. $\mathrm{No}$ reconhecimento deste facto e na consequente explicitação dos seus sentidos possíveis se resume grande parte do esforço leibniziano para encontrar uma solução para os problemas filosóficos que a necessidade coloca. Só o reconhecimento de que existem diversas formas ou graus de necessidade permitirá conciliar teses que do ponto de vista da univocidade se revelam opostas e inconciliáveis, mas que, de outro ponto de vista, nomeadamente o teológico, são irrenunciáveis. Por isso, entre os objectivos da Teodiceia, Leibniz incluía o de distinguir os diferentes tipos de necessidade, para detectar aqueles que são incomR ecebido em maio de 2005. A ceito em junho de 2005.

doispontos, Curitiba, São Carlos, vol. 2, n. 1, p.53-82, outubro, 2005 


\section{4}

patíveis com a liberdade e a moralidade e aqueles que são exigidos por elas'. Leibniz utiliza o plural, referindo-se a graus de necessidade, dando a entender que há várias formas de necessidade absoluta e diversas formas de necessidade relativa?2.

C onfundindo-se os significados dos termos necessário e necessidade, tomando-se como unívoco um conceito não unívoco, transformaram-se estes conceitos em conceitos equívocos; não admira então que os debates em torno da liberdade, a presciência e a justiça divina, etc., pareçam indecidíveis3. Trata-se na realidade de debates estéreis, debates que se esfumariam logo que se precisasse exactamente 0 sentido da necessidade que em cada caso está em jogo.

Apesar de denunciar continuamente esta fonte de erros desnecessários, o próprio Leibniz não usa sempre com o mesmo rigor os termos "necessário" e "necessidade": quase com a mesma frequência com que se refere às diferentes formas de necessidade e exige que se identifique aquela que em cada caso é pertinente, refere- se à necessidade sem qualificá-la de nenhum modo, como se a este conceito correspondesse em todos os casos uma única definição 4 . É certo que a imprecisão, embora frequente, se esclarece habitualmente pelo contexto e à luz das diversas classificações desta noção que Leibniz explicita em muitos momentos; trata-se, contudo, de uma ambiguidade que seguramente não é alheia à própria multiplicidade de interpretações a que o leibnizianismo deu origem.

Por outro lado, mesmo quando o usa no singular, sem qualificativos, e aponta para um núcleo comum a todas as formas de necessidade, Leibniz não considera o conceito de necessidade como um conceito unívoco, ou dotado de um único significado; propõe várias definições do necessário e da necessidade, definições que não são inteiramente independentes, mas que constituem outras tantas caracterizações da noção de necessidade em cada uma das diversas perspectivas de abordagem das modalidades que Leibniz tem em conta, e que não se confundem ou substituem umas às outras.

b) M ultiplicidade de sentidos

T ão importante como evitar os equívocos na caracterização da necessidade, é acentuar a multiplicidade dos seus sentidos, estabelecer o seu 
carácter não unívoco. Com efeito, Leibniz considera que se o conceito de necessidade fosse um conceito unívoco haveria que renunciar a uma explicação da realidade no seu todo ou nalgum dos seus aspectos. N essa hipótese inaceitável ou tudo seria igualmente necessário e seria explicá vel (e a contingência e a liberdade seriam impossibilidades metafísicas) ou o que não é necessário careceria absolutamente de explicação (e a contingência e a liberdade seriam irracionais). $M$ as 0 necessitarismo é uma solução simplista, que sacrifica, sem o explicar, um dos termos do conflito, e a contingência assim entendida implicaria uma renúncia à inteligibilidade, uma renúncia à explicação. U ma tematização da necessidade capaz de dar conta simultaneamente da inteligibilidade do real e dos âmbitos de contingência que nele se verificam tem portanto de enquadrá-la entre estes dois extremos. Para isso, o termo necessidade deverá estar dotado de uma multiplicidade de significados5, e por isso Leibniz indicava, como vimos, no início da Teodiceia, que um dos seu objectivos era mostrar que a necessidade admite graus, que há formas de necessidade que são incompatíveis com a liberdade e outras que não, chegando inclusivamente a afirmar que a explicitação dos sentidos desse conceito é o objectivo real da obra6.

Leibniz serve-se de uma enorme variedade de expressões para caracterizar, nos seus múltiplos sentidos, a necessidade. Considerando unicamente a Teodiceia, poderiam referir-se, entre outras, as seguintes: necessidade prejudicial à prática, necessidade fatal, necessidade insuperável, necessidade natural, necessidade absoluta, também chamada lógica e metafísica e às vezes geométrica, necessidade absol uta ou verdadeira necessidade, necessidade hipotética e necessidade moral, necessidade cega e totalmente geométrica, necessidade absolutamente geométrica, necessidade suprema, necessidade inteiramente matemática, necessidade bruta e cega, feliz necessidade do sábio, etc. $\mathrm{N}$ ão se trata, naturalmente, duma apresentação exaustiva das matizações da necessidade, nem cada uma destas expressões indica um grau diverso da necessidade muitas delas são designações diversas da mesma forma de necessidade mas a abundância de adjectivos com que caracteriza este conceito revela que Leibniz admite formas diversas de necessidade, às quais subjaz uma classificação do conceito - ou várias - que nem sempre é explicitada.

De outra perspectiva, a noção de necessidade diversifica-se também em função dos objectos aos quais se aplica. Também neste caso, a necessi- 
dade aparece em múltiplos contextos. por referir também apenas a Teodiceia, a necessi dade refere-se ao destino, às coisas, à predeterminação (que pode ser necessitante), às verdades eternas absolutamente necessárias, às leis, aos argumentos, ao ser necessário e à sua natureza, às causas, e diz-se ainda de certas permissões (por exemplo, do mal), das obrigações, de alguns princípios (há o princípio do necessário), de certos meios e fins, da própria possibilidade (é necessário que seja possível algo, por exemplo responder às objecções contra os dogmas), do sistema da harmonia, etc..

A multiplicidade de registos em que opera, com adaptações, 0 conceito de necessidade permite ainda reconhecer-Ihe uma dimensão activa, recolhida no verbo necessitar. Este verbo aparece na Teodiceia com dois sentidos fundamentais: "causar necessidade" ou "estar necessitado de", consoante a necessidade surgida da relação entre 0 agente e 0 paciente se analise do ponto de vista do primeiro ou do segundo.Tratase de sentidos correlativos, mas independentes, do termo necessitar. É neste contexto que Leibniz se refere, por exemplo, à existência de razões não necessitantes e afirma que não estamos necessitados pela presença da causa.

É interessante assinalar ainda, e talvez sobretudo, que Leibniz não apresenta uma única classificação dos sentidos da necessidade. I sto significa que a pluralidade de significações da necessidade se pode estabelecer de pontos de vista diversos e, se as diversas classificações não forem totalmente sobreponíveis, significa também que há diferentes razões pelas quais algo se pode dizer necessário; deste modo, o que segundo um determinado critério não é necessário, segundo outro critério pode eventualmente ser assim designado. A preocupação leibniziana por introduzir formas de necessidade não incompatíveis com a contingência orienta claramente a sua posição neste sentido.

\section{Classificações da necessidade}

Além de múltiplas, as classificações leibnizianas da necessidade apresentam frequentemente variantes e não são formuladas sempre nos mesmos termos. Sem a pretensão de esgotar essas classificações, poderiam referir-se: 1) a distinção entre necessidade absoluta e necessidade hipotética; 
2) a distinção entre necessário por si e necessário por analogia;

3) a distinção entre necessidade do consequente e necessidade da consequência;

4) a distinção entre necessário por si e necessário por outro;

5) a distinção entre necessidade metafísica, física e moral;

$N$ ão se trata de classificações de épocas diferentes da vida de Leibniz ou de uma eventual actualização linguística. Todas as classificações referidas se encontram na Teodiceia, o que leva a crer que Leibniz não estabelece uma correspondência exacta entre as diversas classificações. É possível pensar que algumas delas se sobrepõem, correspondendo a pontos de vista diversos de consideração da necessidade, ou a âmbitos específicos de aplicação do conceito. M as é possível admitir também que estas classificações assentam em critérios diversos, critérios que, permitindo distinguir formas diversas de necessidade, permitirão igualmente identificar aquilo em virtude do qual algo se diz necessário.

D as classificações apresentadas, só uma admite três termos. D aí que a advertência de Leibniz no prefácio da Teodiceia leve a pensar que nenhuma das classificações esgota o leque de significados do termo e que haverá que considerar simultaneamente várias classificações, ou todas elas, para dar razão de todos os modos de dizer o necessário. Com efeito, nesse texto, Leibniz indicava, como se ressaltou, que esperava provar que há formas de necessidade incompatíveis com a contingência e formas de necessidade que o não são. 0 duplo plural permitiria esperar uma classificação com pelo menos quatro termos, que não se encontra na Teodiceia, nem em nenhuma outra obra. As classificações mais frequentes distinguem dois ou, no máximo, três sentidos da necessidade. $H$ averá que admitir portanto que a multiplicidade de sentidos da necessidade se obtém a partir de pontos de vista diversos e independentes de classificação deste conceito; há várias classificações porque há diversos critérios que permitem atribuir a necessidade a algo que se diz necessário.

a) N ecessidade hipotética e necessidade absoluta

A distinção entre necessidade absoluta e necessidade hipotética é talvez a mais frequentemente invocada por Leibniz, o qual considera que a correcta compreensão desta distinção basta para resolver a maioria das dificuldades que a questão das modalidades coloca; é ela que permite 
compreender como se assegura simultaneamente a presciência e a contingência, pondo em destaque que a presciência é uma forma de necessidade hipotética fundada na certeza do conhecimento, forma de necessidade que é compatível com a ausência de necessidade absoluta, isto é, com a contingência das realidades pré-conhecidas.

0 próprio da necessidade absoluta é que não depende de nenhuma condição, nem sequer da hipótese da presciência; encontra-se naquilo cujo oposto é contraditório em si mesmo. Pelo contrário, a necessidade introduzida pela presciência não afecta os possíveis em si mesmos, atribuise-Ihes apenas pelo facto de serem pré- conhecidos. M as isto significa que é uma necessidade derivada, condicionada à própria previsão e remetendo para ela. Supor que tal previsão confere necessidade ao objecto conhecido equivaleria a aceitar que a presciência altera a natureza do que conhece, equivaleria em última instância a negar a presciência ou a declarar D eus incapaz de conhecer o contingente, já que transforma em necessário aquilo que contempla. 0 oposto da necessidade hipotética é também nalgum sentido contraditório, mas não é contraditório em si mesmo; a contradição só surge porque se admite como verdadeira a hipótese, em si não necessária, com a qual ele entra em contradição.

Há diversas variantes desta classificação: estão nesse caso as distinções entre necessidade incondicional e necessidade condicional ${ }^{7}$ e entre necessidade absoluta e necessidade da consequência. A necessidade absoluta dá-se quando o contrário da coisa implica contradição; a necessidade da consequência é a que se atribui ao que se segue como consequência necessária de outra coisa (em si necessária ou não)8. Leibniz não identifica neste texto, como fará noutros casos, a necessidade absoluta e a necessidade do consequente 9 , provavelmente porque a necessidade absoluta não é sempre necessidade do consequente, embora a necessidade do consequente seja uma forma de necessidade absoluta.

A distinção entre necessidade absoluta e necessidade hipotética corresponde de algum modo à distinção entre necessário por si e necessário por outro, se se tiver em conta que o necessário por si é necessário incondicionalmente e o necessário por outro o é condicionadamente.

A necessidade absoluta define-se exclusivamente pela referência ao princípio de contradição, por isso é considerada uma necessidade incondicional, posto que este princípio não introduz nenhuma condição, 
expressando as exigências mínimas, aqui suficientes, da inteligibilidade. $\mathrm{N}$ a medida em que se define pela referência exclusiva ao princípio de contradição a necessidade absoluta pode ser chamada lógica, posto que é por uma exigência da lógica que algo se diz absolutamente necessário.

Leibniz caracteriza de diversas formas a necessidade absoluta; são frequentes, por exemplo, as expressões "necessidade cega", "necessidade bruta", as quais apontam para um processo necessitado integralmente pelas condições antecedentes, um processo no qual o desenlace é único e não são pensáveis desenlaces alternativos. A necessidade absoluta aproxima-se deste modo da coacção e exclui a escolha ou a deliberação, a consideração do fim; por isso se diz que carece de lei, ou que ela própria é lei, pois nada exterior pode condicionar o que não admite alternativa.

$\mathrm{N}$ alguns textos Leibniz integra estes sentidos da necessidade numa classificação tripartida. Fá-lo, por exemplo, nas $R$ emarques sur le Livre de I'origine du mal, ...., indicando que é preciso distinguir entre a necessidade absoluta - contrária à moralidade - , a necessidade hipotética e a necessidade moral. A distinção é mencionada quando se consideram os requisitos do exercício da liberdade. $\mathrm{N}$ a sua crítica Leibniz considera que os dois requisitos referidos - ausência de constrições externas ou ausência de coacção e ausência de necessidade interna - são insuficientes porque a noção de necessidade interna pode entender-se em sentidos diversos ${ }^{10}$. Com efeito, se é verdade que o absolutamente necessário está dotado de necessidade interna, é igualmente verdade que a própria vontade livre está dotada de uma certa necessidade interna, porque é levada a escolher pelo seu objecto próprio, o bem real ou aparente. D este ponto de vista, necessidades tão diferentes como a necessidade absoluta e a necessidade moral coincidem em ser internas, embora o carácter interno da necessidade se entenda em ambos os casos de modo diverso. Só a necessidade hipotética, aqui entendida como necessidade física, não é uma necessidade interna mas uma necessidade externa, fundada em algo exterior àquilo que se diz necessário.

0 mesmo acontece nas $R$ eflexions sur l'ouvrage que M . H obbes a publié en A nglois, de la Liberté, de la $\mathrm{N}$ ecessité et du $\mathrm{H}$ azard. $\mathrm{N}$ esse texto Leibniz considera a oposição entre necessidade hipotética e necessidade absoluta, mas acrescenta ainda a referência à necessidade moral e a uma necessidade de ordem física, que ele qualifica como cega11. C riticando as consequên- 
cias necessitaristas que $\mathrm{H}$ obbes extrai do princípio de razão suficiente, e que 0 levam a afirmar que a presciência basta para fundamentar a necessidade absoluta, Leibniz começa por distinguir a necessidade hipotética "que vem da presciência ou de outras razões anteriores" da necessidade daquilo cujo contrário implica contradição e que faz com que a coisa seja necessária por si mesma. E prossegue: "O Sr. H obbes também não quer ouvir falar de uma necessidade moral, pois de facto tudo acontece por causas físicas. M as há razão para estabelecer uma grande diferença entre a necessidade que obriga o sábio a agir bem, que se chama moral, e que tem lugar mesmo relativamente a Deus, e esta necessidade cega, pela qual Epicuro, Estratão, Spinoza e talvez o Sr. H obbes pensaram que as coisas existiam sem inteligência e sem escolha, e consequentemente sem D eus" 12. A argumentação conclui-se com o reconhecimento e a justificação do carácter absoluto desta necessidade cega.

0 texto contém diversos elementos significativos. Leibniz identifica a necessidade hipotética como a necessidade fundada na presciência, e não inclui nela nem a necessidade física nem a necessidade moral. A necessidade hipotética assim entendida distingue-se da que corresponde às coisas que são necessárias por si mesmas e cujo oposto implica contradição.

À margem desta distinção, o texto estabelece ainda a distinção entre necessidade moral, a qual contém uma obrigação de razão e é feliz e desejável, e a necessidade cega que se pode atribuir aos acontecimentos quando se aceita que tudo sucede por causas físicas. A segunda é também uma necessidade absoluta, "porque tudo o que ela traz consigo deve suceder, faça-se 0 que se fizer" 13 .

Conjugando as duas classificações, a partir do seu elemento comum, 0 objectivo de Leibniz é evidenciar que a necessidade moral é condição necessária e suficiente da distinção entre necessidade absoluta ou necessário por si mesmo e necessidade hipotética, fundada em razões exteriores. Com efeito, o recurso à necessidade hipotética, se não vai acompanhado da admissão simultânea da necessidade moral, transforma aquela numa necessidade cega e absoluta, em virtude da qual as coisas existiriam pela sua mesma essência e não por uma escolha. D esta perspectiva, a rejeição da necessidade moral conduz sempre à negação da contingência, e o carácter eventualmente derivado da necessidade hipotética não tiraria nada à dimensão necessitante de todo o processo. 
A necessidade hipotética estabelece a dependência do fim relativamente aos meios e permite justamente afirmar a responsabilidade da autoria dos actos livres. Como é bem sabido, os defensores do sofisma da razão preguiçosa negaram precisamente essa dependência considerando que algo sucederá necessariamente façamos nós o que fizermos. Em lugar desta fatalidade absurda haverá que estabelecer a necessidade hipotética em virtude da qual algo sucede porque se deram as causas que 0 produzem. $\mathrm{N}$ alguns textos, Leibniz chega mesmo a identificar a necessidade com a utilidade: algo é necessário para um fim porque é um meio - o único ou simplesmente o mais conveniente - de o obter ${ }^{15}$.

0 próprio da necessidade absoluta é que é incondicionada, situa-se no plano dos possíveis e remete para o que neles seria contraditório se fosse negado. A necessidade hipotética apresenta-se como uma necessidade derivada, a qual supõe - indica Leibniz - decretos possíveis da vontade divina e surge com eles. A consequência só é necessária na medida em que esses decretos se consideram efectivos ou verdadeiros. $\mathrm{N}$ ão basta considerá-los como possíveis. N essa medida, a necessidade hipotética situa-se no plano dos possíveis mas aponta para a (possível) realização efectiva de um mundo. Só na medida em que a vontade divina intervém na determinação de um possível se pode falar de necessidade hipotética; mas a vontade divina intervém definindo critérios possíveis de preferência ou de escolha, remetendo portanto de algum modo para a possibilidade da criação.

A distinção entre necessidade absoluta e necessidade hipotética não corresponde portanto a uma repartição entre seres absolutamente necessários e seres hipoteticamente necessários mas define para cada possível e para cada mundo o que é absolutamente necessário e escapa ao poder da vontade divina, que a ela se sujeita, e o que é necessário por uma determinação dessa vontade, porque foi escolhido.Todos os possíveis individuais participam destas duas formas de necessidade e não seriam pensáveis sem elas.

Pode afirmar-se que a necessidade absoluta é a mais básica forma de necessidade, ou mesmo que é a única verdadeira forma de necessidade, na medida em que pode explicitar-se sem referência a outras formas de necessidade, ao passo que as outras não poderão explicitar-se sem refe- 
rência à necessidade absoluta. C ontudo, Leibniz caracteriza frequentemente as outras formas de necessi dade negando expressamente a necessidade absoluta16.

\section{b) A necessidade por si e a necessidade por analogia}

N o A bregé de la controverse..., Leibniz apresenta uma outra classificação dos sentidos da necessidade na qual distingue a necessidade geométrica ou metafísica e totalmente absoluta e a necessidade por analogia ou necessidade moral. Diz assim:

"Embora a sua (divina) vontade seja infalível e se dirija sempre ao melhor, o mal, ou o bem menor que ele rejeita, não deixa de ser possível em si; caso contrário a necessidade do bem seria geométrica (por assim dizer) ou metafísica e totalmente absoluta, a contingência das coisas seria destruída e não haveria escolha. $M$ as este tipo de necessidade que não destrói a possibilidade do contrário, recebe este nome apenas por analogia, torna-se efectiva, não apenas pela essência simples das coisas, mas pelo que se encontra fora delas e acima delas, a saber, pela vontade de D eus. Esta necessidade é chamada moral, porque no sábio necessário e devido são coisas equivalentes" 17.

É interessante assinalar, por um lado, que a classificação dos diferentes tipos de necessidade referida neste texto não se limita ao âmbito das verdades: a necessidade predica-se de um objecto, 0 bem, enquanto termo da vontade divina eficaz. Por outro lado, ao distinguir entre necessidade por si e necessidade por analogia, Leibniz considera a necessidade do ponto de vista do que a instaura - a essência das coisas ou a vontade de Deus - e não do ponto de vista dos efeitos, das proposições que em virtude da necessidade se podem enunciar como verdadeiras.

0 critério que permite distinguir as duas formas de necessidade é um critério negativo e remete para a possibilidade do contrário. D este ponto de vista a classificação é exaustiva: há uma forma de necessidade que não admite a possibilidade do contrário e outra que não destrói essa possibilidade. No primeiro caso, a necessi dade é "geométrica, metafísica e totalmente absoluta". É a necessidade oposta à contingência e incompatível com ela. $\mathrm{N}$ o segundo caso, a necessidade não destrói a possibilidade do contrário e, admitindo-a, instala-se no âmbito do contingente, o qual permite e exige uma escolha, que introduz uma certa necessidade. É uma 
necessi dade que não se fundamenta apenas na essência das coisas mas que remete para algo exterior e superior: a vontade divina.

0 que confere carácter necessário ao bem é a infalibilidade que se reconhece à determinação da vontade na sua escolha livre; por isso, esta necessidade não destrói a possibilidade do mal, mas pressupõe-a. A necessidade do bem é a necessidade própria do devido, do que pode - mas não deve - ser de outro modo, e que seguramente não será de outro modo se 0 agente for sábio.

A necessidade absoluta situa-se à margem da contingência e opõe-se a ela; a necessidade por analogia situa-se no âmbito do contingente e éIhe interior, é um princípio interno de determinação do contingente. $A$ primeira remete para a essência simples das coisas, a segunda exige algo mais, a suposição do exercício da vontade divina.

0 necessário por analogia não se enquadra na definição do necessário que faz referência à contradição do oposto e por isso não é em sentido próprio uma autêntica necessidade. 0 seu carácter necessário significa que se trata de algo infalível, mas de uma infalibilidade de facto, que é efectividade. A necessidade por analogia é-o porque o seu contrário, sendo possível em si mesmo, é de facto não existente e se conhece como tal. N este sentido pode falar-se de indispensabilidade do que acontece, mas trata-se de uma indispensabilidade derivada e não originária. 0 que se opõe à necessidade por analogia é possível por si e impossível por outro, em virtude de uma razão exterior que o declara inexistente de facto. Em sentido rigoroso, portanto, a necessidade por analogia é assim chamada apenas por ser um modo inteligível da contingência, o único modo possível do contingente ser acessível.

$\mathrm{N}$ a medida em que, por contraposição, o necessário faz referência ao possível em si, aquele caracteriza-se como necessário em si mesmo, ou necessário pela essência, e o necessário analogicamente é necessário, não em si, mas por algo exterior. 0 necessário absolutamente opõe-se ao impossível em si mesmo, ao contraditório; o necessário por analogia distingue-se do efectivamente inexistente, e portanto falso, e delimita no âmbito do possível o que existe e podia não ter existido.

c) N ecessidade do consequente e necessidade da consequência

0 utra classificação das formas de necessidade resulta de se rejeitar a 


\section{4}

dicotomia entre 0 que acontece por necessidade e 0 que acontece por acaso. $N$ este contexto a necessidade não é qual ificada e significa manifestamente a necessidade absoluta. A classificação a que a tematização da necessidade dos acontecimentos dá origem leva então a distinguir dois tipos de necessidade que se situam em planos diferentes: a necessidade do consequente e a necessidade da consequência18.

Leibniz opera com esta distinção desde muito cedo e ela reaparece continuamente, embora nem sempre de forma explícita, na Teodiceia. 0 problema filosófico para o qual esta distinção é esclarecedora é o da possível determinação da modalidade que convém ao mundo, admitindose a presciência divina. Trata-se de conciliar o carácter necessariamente verdadeiro de uma proposição (a enunciada por D eus e que faz d'Ele um ser omnisciente, e não um adivinho, havendo portanto um fundamento para a sua omnisciência) com a modalidade do acontecimento que na proposição se enuncia. A distinção entre necessidade da consequência e necessidade do consequente estabelece-se para poder justificar que "embora D eus preveja um acontecimento futuro, não é necessário que ele aconteça" 19 .

0 próprio desta classificação é que ela se coloca e se estabelece no âmbito de uma inferência, distinguindo-se a necessidade da própria inferência, necessidade que se poderia chamar formal ou lógica, e a necessidade do inferido ou da conclusão, ou distinguindo a necessidade da argumentação da necessidade própria do que se concluiu de forma necessária. Aqui a necessidade lógica aplica-se ao âmbito do contingente, ou melhor ao nosso modo de conhecer 0 contingente. $\mathrm{H}$ á raciocínios absolutamente necessários acerca do contingente, porque num raciocínio correcto há sempre a necessidade proveniente do encadeamento inviolável das verdades nele vinculadas. É dessa natureza o argumento que diz que não pode deixar de verificar-se o que D eus previu que se verificaria, isto é, o argumento que afirma que certamente se dará o que o ser omnisciente conhece como verdadeiro e futuro. Esta relação necessitante entre as proposições é independente do conteúdo proposicional ao qual ela se aplica; é neste sentido que se diz que a conclusão não excede nunca em universalidade e necessidade a mais débil das premissas.

A necessidade da consequência refere-se à correcção da inferência; a necessidade do consequente remete para o conteúdo inferido no 
raciocínio. A primeira é uma necessidade de dico e aplica-se à totalidade do raciocínio, sendo-Ihe exterior. A necessidade do consequente é uma necessidade de re e remete para a modalidade própria do conteúdo concluído, ou do acontecimento que na conclusão se enuncia.

Ao estabelecer esta distinção, Leibniz estabelece ao mesmo tempo a relação das duas formas de necessidade. A firma:

"a necessidade da consequência não impede que 0 acontecimento ou 0

consequente seja em si contingente" 20 .

A distinção de Leibniz permite desvincular a necessidade própria do conhecimento, mesmo hipotético, da modalidade própria do conhecido, e estabelece em concreto a possibilidade de que um conhecimento necessariamente verdadeiro tenha como objecto uma realidade contingente. $N$ este sentido, 0 consequente é contingente por si e necessário por outro, em virtude da verdade das proposições de que ele é a conclusão, isto é, a proposição que enuncia a conclusão é hipoteticamente necessária mas o conteúdo enunciado é em si mesmo contingente, poderia ser falso se as premissas fossem falsas.

A característica específica desta classificação da necessidade é que distingue dois planos da necessidade: 0 dos enunciados e 0 dos referentes desses enunciados. A o distinguir estes dois tipos de necessidade é possível considerar que no plano dos enunciados algo é necessário e que no plano dos factos aquilo de que se fala seja contingente ou não necessário. A necessidade da implicação não pressupõe nem exige a necessidade dos termos implicados e não se lhes transmite, é a necessidade do todo, supos ta a verdade do antecedente e a correcção da inferência.

Leibniz desenvolve amplamente esta distinção ao estabelecer a compatibilidade entre omnisciência e contingência, e mais concretamente a compatibilidade entre a omnisciência e a liberdade, e a distinção é por ele apresentada precisamente como a chave que permite resolver este difícil problema. $\mathrm{N}$ o núcleo da distinção leibniziana está a consideração de que o facto de ser conhecida é para uma realidade uma propriedade acidental, a qual não afecta a modalidade que lhe corresponde por essência. 0 conhecimento divino - sendo necessariamente verdadeiro e prévio ao acontecimento - não altera o carácter necessário, contingente ou livre do seu objecto, capta-o sem 0 alterar. Se esta verdade 
se nega, declaram- se incompatíveis $D$ eus e a contingência, porque $D$ eus não pode deixar de ser omnisciente, e portanto, se a omnisciência fosse necessitante dos acontecimentos, tudo seria igualmente necessário e nada seria realmente contingente.

$\mathrm{N}$ alguns aspectos, a distinção entre necessidade do consequente e necessidade da consequência pode assimilar-se à que existe entre necessidade absoluta e necessidade hipotética. Poder-se-ia falar de necessidade absoluta ou do consequente se se estabelecesse que uma única ordem de coisas é possível, e isto tanto no plano da existência como no plano da acção. Pelo contrário, se a necessidade for tal que só se verificará se 0 antecedente se aceitar como verdadeiro ou existente, podendo não sê-lo, a necessidade será apenas hipotética ou da consequência.

A necessidade da consequência pressupõe a contingência dos elementos que por meio dela se vinculam, isto é, pressupõe que 0 antecedente poderia de facto não ser posto (e portanto o consequente também não); por outro lado, o consequente, determinado pela necessidade hipotética, é em si contingente, uma vez que 0 vínculo que une 0 antecedente ao consequente não anula a possibilidade do seu oposto, mas a pressupõe. Também aqui, a possibilidade da existência e da não existência de algo é prévia e independente das causas ou das condições que o determinam à existência e não se altera por elas. A lém disso, em virtude do anterior, 0 próprio vínculo não é necessitante, mas apenas determinante ou inclinante. $D$ aí que Leibniz considere que 0 vínculo que une 0 antecedente ao consequente não confere necessidade, nem sequer hipotética, a não ser que se afirme que a inclinação prevalecente vence sempre.

d) N ecessário por si e necessário por outro

A distinção entre necessário por si e necessário por outro corresponde também de algum modo à distinção entre necessidade absoluta e necessidade hipotética, mas as duas distinções não se identificam totalmente. Teoricamente algo poderia ser necessário por outro e ser absolutamente necessário. Foi assim que Spinoza entendeu a criação, segundo Leibniz. Foi assim que a entenderam também todos os que rejeitam a tese da existência de uma infinidade de mundos possíveis. Certamente, o que é necessário por outro é necessário derivadamente, mas Leibniz considera que este carácter derivado da necessidade não basta para assegurar a 
contingência, e por isso mantém que o que assegura a contingência é a sua tese de que há possíveis que nunca existirão. 0 contingente é sempre necessário por outro e não pode, por definição, ser necessário por si, mas para que algo necessário por outro seja contingente é preciso assegurar que a sua causa podia não agir e podia agir de outro modo.

Dito de outro modo, a necessidade absoluta e a necessidade hipotética só se distinguem suficientemente se a hipótese e o vínculo entre a hipótese e a consequência puderem ser de outro modo, caso contrário a distinção é meramente verbal. Por isso, Leibniz considera que as posições de D escartes e Spinoza são na realidade posições necessitaristas. A necessidade absoluta revela-se no campo do devir como uma necessidade por outro que não admite alternativas. A necessidade que Spinoza atribui ao mundo é deste tipo e esta é também a necessidade que deveria atribuirse aos processos da natureza se se aceitasse a tese cartesiana de que a matéria assume com o tempo todas as formas possíveis.

e) $\mathrm{N}$ ecessidade metafísica, necessidade física e necessidade moral

As classificações anteriores põem em relevo que o conceito de necessidade obedece nos textos de Leibniz a uma clivagem básica: clivagem que leva a distinguir entre necessidade absoluta e uma necessidade não absoluta ou relativa, a que se chamará hipotética. Diz-se dela que é rela tiva ou hipotética porque tem o seu fundamento na hipótese - em si não necessária - de que uma determinada circunstância ou situação se dá e é relativa a essa hipótese. Como vimos, nalguns casos, os termos variam mas as classificações sobrepõem- se: tal é o caso da distinção entre necessidade autêntica e necessidade por analogia. 0 utras classificações, apresentandose embora, como sinónimas destas, são na realidade uma sua aplicação a âmbitos determinados da realidade: assim, falando do destino e da vida humana, Leibniz contrapõe a necessidade insuportável (correspondente para este âmbito à necessidade absoluta) à necessidade feliz; ou, referindose às constrições a que pode eventualmente estar sujeita a acção livre, distingue entre verdadeira necessidade e necessidade moral.

Junto a esta classificação bipartida, encontra-se com muita frequência nos textos de Leibniz uma outra classificação, mais matizada, que distingue entre necessidade metafísica, necessidade física e necessidade moral. N ela se explicita uma segunda clivagem fundamental, que se insere 
no âmbito da necessidade relativa, e que leva a distinguir a necessidade física da necessidade moral. Deste ponto de vista, esta classificação embora exigida pela ontologia leibniziana - não acrescenta de facto nada novo à tematização da necessidade em si mesma, e ao propô-la Leibniz limita-se a explicitar os dois âmbitos fundamentais da necessidade hipotética, 0 mundo material e 0 mundo das substâncias inteligentes. $\mathrm{N}$ ão se trata propriamente de modos diversos de dizer o necessário mas de reinos diversos de aplicação duma mesma necessidade hipotética. Distinguem-se, por serem no essencial diversos na sua acção os seres aos quais a necessidade hipotética se aplica. Leibniz vincula-as, sem as identificar, ao afirmar explicitamente que a necessidade física se fundamenta na necessidade moral ou que a necessidade moral dá razão da necessidade física21. A primeira dá razão da regularidade da república dos espíritos, a segunda expressa a regularidade da máquina do mundo. D e outro modo, o poder determinante da causalidade final justifica - e só ele é capaz de o fazer no âmbito do contingente - o modo de determinação da causalidade física.

Trata-se de uma classificação frequente na Teodiceia; no $\S 2$ do D iscours Preliminaire, Leibniz expõe-a nos seguintes termos:

"as verdades da R azão são de dois tipos: umas são as chamadas Verdades E ternas, que são absolutamente necessárias, de tal modo que o oposto implica contradição; estas são asVerdades cuja necessidade é lógica, metafísica, geométrica, as quais não se podem negar sem se poder ser conduzido a absurdos. Há outras que se podem chamar Positivas, porque são as leis que agradou a D eus dar à natureza, ou que dependem delas. Conhecemo-las ou por experiência, isto é, a posteriori, ou pela razão e a priori, isto é, pelas razões de conveniência que as fizeram escolher. Esta conveniência tem também as suas regras e razões, mas é a escolha livre de Deus, e não uma necessidade Geométrica, que faz preferir o conveniente, e o conduz à existência. Assim, pode-se dizer que a necessidade física se funda na necessidade moral, isto é, na escolha do sábio digno da sua sabedoria; e que tanto uma como a outra se devem distinguir da necessidade geométrica"22.

0 texto merece uma análise atenta. Leibniz distingue dois tipos de verdade e três tipos de modalização necessitante destas verdades: há as 
verdades eternas e as positivas, mas há a necessidade metafísica, a necessidade física e a necessidade moral. A dicotomia das verdades reflecte-se, contudo, na própria classificação das formas de necessidade, uma vez que entre a necessidade física e a necessidade moral há uma dupla relação: relação de conveniência pela qual coincidem em se distinguir da necessidade geométrica e uma relação de dependência ou de fundamentação: a necessidade moral fundamenta a necessidade física, e portanto esta depende daquela. A clivagem entre verdades eternas e verdades positivas corresponde, portanto, a uma oposição entre necessidade metafísica (absoluta, lógica, geométrica, escreve também Leibniz) e uma necessidade não metafísica, na ocorrência física ou moral.

$\mathrm{N}$ o texto, todos os sentidos da necessidade referidos se situam no âmbito das chamadas verdades de razão. Leibniz enquadra-as entre as verdades da fé e as verdades que têm o seu fundamento na experiência. $M$ as na realidade não se trata de uma dupla delimitação do âmbito das verdades de razão ou do âmbito do necessário, porque há uma tão íntima conexão entre a experiência e a fé - as razões de credibilidade remetem para a experiência, para a experiência fáctica dos milagres, etc., e em ambos os casos conhece-se que algo é verdadeiro sem conhecer as razões que fundamentam a sua verdade - que se pode dizer que as verdades de razão, no seio das quais as diferentes formas de necessidade se diferenciam, se distinguem unicamente das verdades de facto ou de experiência, em virtude da inevidência intelectual e da imediatez fáctica destas últimas.

Por outro lado, Leibniz está interessado no contexto do debate desenvolvido na Teodiceia, em distinguir as verdades cuja necessidade se compreende daquelas cuja necessidade se conhece sem se compreender. A mbas se distinguem das verdades cuja necessidade se desconhece, e essas são as verdades de facto. Aí, nas verdades de experiência, não há elementos suficientes para se fundamentar um conhecimento universal e necessário, pois a indução não garante nunca a necessidade. A plicada, como no contexto acontece, ao âmbito das verdades, a necessidade instala-se, modalizando-se, no âmbito das verdades de razão, deixando de fora todo o âmbito do conhecimento experiencial, o qual é incapaz, em virtude da sua origem, de se libertar da singularidade do facto concreto e de ascender à generalidade e à universalidade. 
D este ponto de vista, a necessidade pertence ao âmbito da verdade, pertencendo ao âmbito da razão, e remete para a forma da verdade, para 0 encadeamento das verdades em que a razão consiste23.

A distinção de graus ou formas de necessidade que convém às verdades de razão parece delimitar três âmbitos da verdade que estão em estreita relação com os objectos. Fala-se de necessidade metafísica, necessidade física e necessidade moral para indicar o tipo particular de necessidade de que estão dotados âmbitos relativamente autónomos de análise que são independentes entre si. M as esta delimitação de áreas de análise do mundo não conduz a classes de equivalência, algo assim como regiões - a M etafísica, a Física e a M oral - que se situem lado a lado e que, conjugadas, constituiriam a totalidade do real.

No âmbito das verdades positivas, a Física e a M oral delimitam certa mente duas áreas de análise conceptualmente diversas: a primeira aplicando-se ao que no mundo criado carece de liberdade, aos movimentos do mundo material nomeadamente, e a segunda aplicando-se aos seres livres, dotados de capacidade de escolha. $M$ as que dizer da necessidade metafísica ou mesmo da necessidade lógica e geométrica? $\mathrm{N}$ ão há uma terceira região independente, não física nem moral, à qual se aplique a necessidade metafísica; pelo contrário, é toda a realidade - física e moral que é globalmente considerada de um ponto de vista metafísico. $\mathrm{N}$ este caso não se considera já uma determinada área da realidade enquanto conhecida, mas considera-se a realidade global de um ponto de vista diverso. Se tal é o caso, a delimitação entre verdades eternas e verdades positivas não corresponde a uma diferenciação entre objectos, dos quais os primeiros seriam absolutamente necessários enquanto os segundos seriam física ou moralmente necessários, mas um mesmo objecto poderá, de um certo ponto de vista, estar dotado de necessidade absoluta e, de outro ponto de vista, estar dotado de necessidade física ou moral.

A necessidade absoluta apresenta-se neste texto como uma propriedade das verdades eternas por se tratar de verdades que são independentes da existência extra mental dos seus objectos. A s verdades absolutamente necessárias são eternas porque a sua negação é contraditória e portanto absolutamente impossível. Em contrapartida, a necessidade física ou moral surge no texto como uma forma de necessidade contemporânea da existência e instaurada por ela; as verdades cuja necessidade é 
física ou moral são positivamente instituídas como verdades, referem-se a existências que, sendo produto de uma escolha, foram consideradas convenientes. À necessidade geométrica opõem-se, portanto, formas de necessidade que, ou se fundamentam numa escolha, ou dão razão da escolha livre. A necessidade física e a necessidade moral situam-se, assim, no âmbito instituído positivamente por uma liberdade, indicando a razão de exercício da liberdade e o seu efeito.

Leibniz explicita algo mais a relação entre a necessidade das verdades eternas e a necessidade das verdades positivas no $\S 4$ do $D$ iscours preliminaire ao indicar que nada pode opôr-se às verdades eternas. A dmitir essa possibilidade seria violar o princípio de não contradição 24 . Portanto, se nalgum caso certas proposições filosóficas se opõem às daTeologia e são rejeitadas por ela, é porque se trata de máximas filosóficas que têm apenas uma necessidade física ou moral, que remetem para o que tem lugar habitualmente 25 .

A classificação dos sentidos da necessidade apresentada neste texto pretende-se exaustiva: qualquer verdade de razão estará dotada de alguma das três formas de necessidade enunciadas e não cabe a possibilidade de que não esteja dotada de alguma forma de necessidade. A razão deste facto encontra-se na circunstância de nos movermos no horizonte das verdades de razão, e onde a razão opera está presente sempre alguma forma de necessidade, mesmo que matizada.

A oposição mais radical nesta classificação tripartida dá-se entre a necessidade metafísica e as outras duas formas de necessidade que se poderiam globalmente considerar como não metafísicas. Por outro lado, há, como se assinalou, uma relação de tipo causal entre a necessidade moral e a necessidade física. Por estas razões Leibniz apresenta frequentemente esta classificação de um modo abreviado, confrontando simplesmente a necessidade metafísica e a necessidade física, ou a necessidade metafísica e a necessidade moral, confronto que se adequa aliás ao que existe entre verdades eternas e verdades positivas que Ihe serve de base, por reter apenas dois elementos. $\mathrm{N}$ este sentido, a primeira forma de necessi dade fundamenta-se unicamente em princípios da razão: o princípio de não contradição e o princípio de terceiro excluído, conjugados, garantem a necessi dade da verdade enunciada; em contrapartida a necessidade física fundamenta-se nas leis que a vontade divina prescreveu à 
natureza, e essa prescrição fundamenta-se por sua vez em razões de sabedoria ou de conveniência.

A distinção entre necessidade física e necessidade moral define-se no âmbito das verdades positivas. É a própria natureza das verdades positivas, em concreto a consideração da sua origem, que obriga a admitir duas formas de necessidade no seu seio e a relacioná-las por uma relação de dependência. As verdades positivas instauram-se, indica Leibniz, por uma escolha livre de Deus. O ra, dentro deste âmbito imenso das verdades positivas podem-se considerar as verdades que dizem respeito ao próprio agente livre e as que dizem respeito à sua obra. A s primeiras referem- se a um acto livre, a uma deliberação ou a uma escolha. As segundas referemse ao resultado ou efeito dessa escolha, ao produzido em virtude dela. $\mathrm{N}$ aturalmente este resultado fundamenta-se na deliberação e não existiria sem ela, sem ter sido escolhido. $M$ as é diferente compreender a escolha feita, enquanto ela surge no agente, e compreender 0 efeito ad extra desse acto livre. $\mathrm{N}$ este sentido a necessidade física fundamenta-se na necessidade moral porque tem nela a sua razão de ser. $\mathrm{N}$ ão pode haver necessidade física sem necessidade moral porque 0 que uma verdade positiva não eterna - enuncia não pode senão ser uma escolha ou fundamentar-se numa escolha, derivar dela. N o primeiro caso a necessidade aponta para as razões que movem $D$ eus a estabelecer verdades positivas, no segundo atribui-se ao que $D$ eus escolheu.

D e outra perspectiva, a estreita relação entre a necessidade metafísica e a necessidade física explicita-se, no contexto teológico da Teodiceia, no parágrafo 23 do $D$ iscurso Preliminar. 0 contexto no qual esta explicitação é levada a cabo procura situar o mistério por relação às verdades de razão e discute desse ponto de vista 0 seu estatuto modal26. Leibniz estabelece aí um duplo paralelismo entre a verdade e a razão, por um lado, e entre esta e a necessidade que caracteriza as verdades, por outro. A necessidade apresenta-se como uma nota da verdade que se refere à razão e que encontra nela o seu fundamento. Do ponto de vista do sujeito cognoscente, as proposições em que se enuncia o mistério são proposições cuja verdade é certa mas cujas razões são desconhecidas. 0 carácter obscuro de tais verdades leva a não as considerar como verdades de razão, entendendo por razão 0 encadeamento inviolável das verdades, posto que do mistério não é possível dar razão27. 
C abe perguntar então que relação têm estas verdades com a razão. Leibniz admite duas possibilidades: ou são verdades que vão contra a razão ou são verdades que estão acima dela. $\mathrm{N}$ ão cabe colocá-las abaixo da razão, em virtude da dignidade da sua origem divina revelada, e porque se trata de verdades teóricas, não práticas. Há, portanto, apenas duas possibilidades, mas a primeira não é uma autêntica possibilidade real; não há, não pode haver, verdades que vão contra a razão; dizê-lo é dizer que há verdades que vão contra a verdade, negar o princípio de não contradição.

0 plano no qual os mistérios se colocam situa-se portanto acima da razão: a razão apresenta-se assim como o âmbito do absolutamente necessário, e os âmbitos da necessidade física e da necessidade moral, embora se expressem em verdades de razão, situam-se de certo modo à margem e acima dela, admitindo um oposto que se situa acima da razão, e que não é portanto inteiramente determinado por ela. $N$ este sentido, a necessidade física e a necessidade moral participam da razão mas não encontram um fundamento suficiente na razão entendida como encadea mento inviolável das verdades: é em virtude dessa fundamentação não puramente lógica - voluntária e positiva - que elas admitem a possibilidade do seu oposto, ou melhor, é porque admitem um oposto que não podem fundamentar-se unicamente na razão.

Paradoxalmente, a este carácter supra racional do mistério corresponde, pelo menos para o homem, um certo carácter debilitado da racionalidade do físico, o qual se expressa na sua condição meramente habitual, positiva, fáctica. 0 carácter meramente habitual expressa, por seu lado, a dependência de uma necessidade moral, obrigada a fazer o conveniente mas não constrangida a seguir sempre as mesmas máximas subalternas que a vontade instituiu.

\section{i) A necessidade metafísica}

0 primeiro termo desta classificação tripartida - a necessidade metafísica - corresponde à necessidade absoluta presente nas classificações anteriores, e, como ela, define-se como a modalidade daquilo cujo oposto implica contradição ${ }^{28}$. A multiplicidade de adjectivos com que é caracterizado este primeiro termo é digna de referência. $A$ necessidade que convém às verdades eternas é chamada absoluta, lógica, geométrica ou metafísica. Leibniz não indica se se trata de sinónimos ou de variantes 
deste primeiro sentido da necessidade, e portanto de âmbitos diversos nos quais está presente uma mesma forma de necessidade. Trata se de designações sinónimas, embora com uma conotação diversa, da mesma forma de necessidade e não de âmbitos diversos e complementares de aplicação de uma certa forma de necessidade.

Esta multiplicidade de designações revela uma nota central da ontologia do autor dos mundos possíveis. Ao tomar como sinónimas as expressões "necessidade absoluta", "necessidade metafísica", "necessidade lógica", Leibniz reconhece na sua génese a natureza epistémica do ser, ou, de outro modo, ontologiza as modalidades. Ser é, antes de mais, ser possível, isto é, ser para um pensamento, ser pensável. 0 âmbito do possível, âmbito do ser em toda a sua amplitude, é a região do pensável, objecto do entendimento divino. Por isso é metafisicamente necessário o que é logicamente necessário e porque o é. A adequação entre ser e pensar é, neste plano, subordinação do ser ao que pode ser pensado, e é expressiva da identidade de estrutura entre o logicamente necessário e 0 ontologicamente real.

$\mathrm{N}$ outras ocasiões Leibniz refere-se à necessidade metafísica caracterizando-a como uma necessidade cega, geométrica, inteiramente matemática. Assim qualificada, a necessidade metafísica caracteriza a acção, o devir e, em geral, os processos a que os seres estão sujeitos. Estas designações explicitam a ausência de alternativa possível no modo do devir dos seres que a ela estão sujeitos, e pode detectar-se sempre que 0 modo de agir de um ser está determinado univocamente e não admite alternativas possíveis. Essa seria a necessidade presente no mundo e na criação se D eus não tivesse tido a possibilidade de escolher.

\section{ii) A necessidade física}

A necessidade física dá-se no âmbito do contingente, do não necessário metafisicamente. É em termos reais e modais um modo de ser do contingente enquanto contingente e funda-se sobre as leis que a vontade divina prescreveu à natureza. A necessidade física é uma forma de necessidade hipotética, a necessidade derivada de um princípio determinante. U m ser está sujeito à necessidade física na medida em que está determinado a ser o que é, a comportar-se segundo uma natureza que tem leis próprias e que só o seu autor pode alterar ou suspender. 
A distinção entre a necessidade metafísica e a necessidade física não corresponde a modos ou formas de realizar um mesmo conceito, referese a modos opostos de diversas realidades possíveis se relacionarem com o princípio de não contradição; em última instância, para Leibniz, o que não é metafisicamente necessário é inteiramente contingente, embora não seja arbitrário; 0 que não é logicamente necessário realiza plenamente a definição do contingente. $D$ aí que o necessário fisicamente se enquadre e estruture o âmbito do não necessário absolutamente, isto é, 0 âmbito do contingente; algo pode ser contingente e, na medida em que o é, ser necessário física ou moralmente.

U $m$ rápido confronto com A ristóteles permitir-nos-á compreender 0 alcance desta caracterização de Leibniz. 0 Estagirita, preocupado ele também em fundamentar e encontrar lugar na natureza para 0 não necessário e a liberdade, ao indicar e definir no livro V, cap. 5 da M etafísica os diversos sentidos da necessidade, afirma o seguinte: "o que não pode ser de outro modo, dizemos que é necessário que seja assim; e segundo este sentido do necessário se dizem também necessárias de certo modo todas as outras coisas" 29 .

Para A ristóteles algo diz-se necessário quando, e na medida em que, não pode ser de outro modo; por isso, quando alguma forma de necessidade hipotética se predica do contingente restringe 0 âmbito da contingência. $\mathrm{N}$ a medida em que algo é necessário hipoteticamente, nessa medida deve-se dizer que o seu oposto deixou de ser possível. Para Leibniz, a situação é diversa: al go diz-se necessário hipoteticamente - física ou moralmente - justamente quando e enquanto pode ser de outro modo. A necessidade física corresponde à afirmação da regularidade do contingente; funda-se em leis escolhidas entre outras possíveis, e que continuam a sê-lo mesmo depois de rejeitadas.

A necessidade física corresponde à chamada necessidade natural; Leibniz utiliza-a para explicitar as exigências que uma determinada natureza comporta e que se revelam no seu modo de agir. Fundamentase nas leis que a vontade divina prescreveu à natureza. Esta necessidade física ou natural pode encontrar-se também ao âmbito dos seres espirituais, porque também a eles $\mathrm{D}$ eus dotou de princípios determinantes do seu modo de agir. D ito de outro modo, é por uma necessidade física que os seres inteligentes actuam moralmente. A necessidade natural é assim 
mais do que a pura necessidade moral, é como uma marca física na substância espiritual.

A necessidade física deriva do exercício da necessidade moral e fundamenta-se nele. Consiste, indica Leibniz, nas regras do movimento ou outras leis gerais que $D$ eus deu às coisas ao dar-Ihes o ser. A necessidade física instaura-se pelo acto criador. As verdades dotadas de necessidade física possuem essa necessidade pelo facto de terem chegado a ser verdades, e 0 que lhes confere necessidade é o facto positivo de terem sido efectivamente queridas. A ntes da existência careciam de forma al guma de necessidade, porque nem sequer existiam como verdades; eram simples possi bilidades de existência, verdades possíveis. A necessidade física é portanto uma necessidade existencial ou fáctica, e a necessidade moral uma necessidade prática, e ambas são exigidas pela contingência.

\section{iii) A necessidade moral}

A necessidade moral corresponde, na expressão de Leibniz, à escolha do sábio que é digno da sua sabedoria. É uma necessidade imposta a uma vontade livre por uma inteligência sábia enquanto tal: corresponde ao conceito de obrigação ou dever moral; moralmente necessário é o conveniente ou o indispensável para a acção boa.

A necessidade moral é a necessidade presente numa escolha e que possibilita, determinando-a, a escolha feita; apresenta-se como um factor ou força de determinação não necessitante do efeito, ou compatível com a liberdade. Está presente em toda a acção livre e não se dá nos seres não livres. No sistema leibniziano é a única forma de necessidade a que está sujeita a acção das criaturas espirituais, enquanto tais. E nelas não pode deixar de estar presente, justamente como condição possibilitante da escolha ou da acção inteligente. $N$ este sentido a necessidade moral exerce-se sobre a escolha e não sobre o efeito da escolha realizada. 0 que é necessário em virtude da necessidade moral é escolher bem, não 0 acto de escolher nem o que é escolhido.

Se a necessidade moral se nega, se se nega o que torna possível a escoIha, haverá que admitir que tudo é necessário absolutamente. Por isso, Leibniz considera que se $D$ eus não fosse um ser inteligente a sua acção causal, 0 acto criador, seria necessitante. Porque D eus produziria sem escolha, e portanto criaria - necessariamente - ou tudo ou nada. Esta 
necessidade encontra- se a meio caminho entre a necessi dade absoluta e a arbitrariedade ou ausência absoluta de regra. N este contexto, a necessidade moral é, como o é também a necessidade física, subordinação (livre) a um princípio, subordinação necessária enquanto conveniente, mas não necessitante. Pela introdução da necessidade moral Leibniz rejeita a alternativa acaso / necessidade. 0 que não é absolutamente necessário não é casual, é antes conveniente 30 .

A necessidade moral corresponde à exigência, livremente acatada, de actuar com autêntica autodeterminação da vontade. A vontade, potência racional de agir, deve à sua natureza a inclinação natural para o bem que a inteligência lhe apresenta. A disposição para o bem constitui-a como faculdade. A necessidade moral é a exigência de realização que se descobre no bem a realizar quando as possibilidades são diversas e os graus de bondade variáveis. Pode e deve ser razão de determinação da vontade, mas só pode sê-lo para uma vontade.

A necessidade moral exprime-se numa obrigação, num dever. 0 moralmente necessário é o devido, exprime a razão da preferência de quem prefere. Dizê-lo é o mesmo que afirmar que o sábio não pode agir senão no respeito pela natureza tendencial da vontade deliberante. 0 carácter tendencial da vontade define-se pelo seu fim - o bem - e em Leibniz isto significa que o sábio não é capaz de agir senão pelas razões do bem. Imaginar - ou desejar - uma vontade que escolhe arbitrariamente é imaginar uma vontade capaz de actuar contra a sua própria natureza, ou desejá-lo por prurido de independência. A arbitrariedade é a própria imagem dessa actuação desvirtuada, auto-aniquiladora, ou, melhor dito, seria, se fosse possível. A arbitrariedade é sinónimo de despotismo e de actuação caprichosa. $M$ as nem o capricho, nem uma indiferença total ou pura são pensáveis no agir moral. Actuar por capricho é ainda actuar por motivos determinantes, mas é determinar-se na submissão, na renúncia à liberdade, porque em tal caso a vontade sujeita-se ou subordina-se às paixões e é determinada por elas; a vontade continuaria a actuar segundo a sua própria natureza (que não está em seu poder alterar) mas não no respeito por essa natureza: movendo-se pela razão de bem, a única que é capaz de mover a vontade, optaria por renunciar ao bem real para aderir ao bem aparente. Por outro lado, a indiferença real ou pura é rigorosamente impensável, isto é, é impossível. 
Admitir tal hipótese é tão absurdo como conferir ao nada força configuradora do real, força produtiva; é pedir ao nada que dê razão, em nome da liberdade, de uma acção que, por ser contingente, precisa duma causa que dê razão dela.

$\mathrm{N}$ a medida em que a necessidade moral é a necessidade que torna possível a escolha, o âmbito de exercício da necessidade moral é 0 âmbito do contingente, do que admite um oposto possível. Deste ponto de vista não é susceptível de qualificativo moral, não pertence ao âmbito da moralidade, o que não admite uma alternativa, o que não pode ser realizado ou omitido ou o que se apresenta relativamente à acção de um ser livre como inevitável. A necessidade bruta e indómita dos estóicos ${ }^{31}$, essa necessidade que não admite lei, não possui qualquer qualificativo moral; o que está dotado de necessidade absoluta, na medida em que escapa ao âmbito da vontade deliberante, apresenta-se sempre como moralmente possível, como lícito. Por isso se pode afirmar que a necessidade é incompatível com a punição32: não é moralmente legítimo punir o agir determinado de forma não livre.

Por último, no âmbito especificamente moral a noção de necessidade como ausência de alternativa possível institui-se por meio de actos como o de obrigar ou de mandar, em virtude dos quais uma acção em si mesma não necessária (física ou metafisicamente) devém necessária (moralmente) ${ }^{33}$. N este contexto a noção de necessidade aproxima-se da de coacção, embora se trate de uma coacção que supõe a liberdade e não a anula; 0 sujeito pode, absolutamente falando, agir de outro modo, mas não pode evitar as consequências indesejadas desse agir. A necessidade apresenta-se portanto como uma forma de condicionamento.

\section{Conclusão}

A análise dos diversos sentidos da necessidade, e mais especificamente, a consideração das classificações da necessidade mais frequentes na de Leibniz, permite pensar que estas classificações correspondem a pontos de vista diversos de consideração da necessidade e de identificação dos factores capazes de conferir necessidade a uma realidade ou a um enunciado. Com efeito, não se trata, como se tentou mostrar, de classificações que 
seja possível sobrepor completamente, pelo que haverá que considerar perspectivas diversas e autónomas de tratamento da necessidade.

A tentativa de reduzir à unidade todas estas classificações - tantas vezes tentada na literatura contemporânea sobre Leibniz - tem conduzido a acusar o filósofo de $\mathrm{H}$ anover de ser incoerente e de não tirar as últimas consequências da sua própria posição. Talvez uma análise detida e cuidadosa da relativa autonomia destas classificações permita pensar noutros moldes a doutrina das modalidades de Leibniz e compreender as razões em que fundamentou a sua defesa sistemática da compatibilidade do determinismo com a contingência.

\section{Cf. LEIBN IZ, 1996 b. p. 37.}

${ }^{2}$ Cf. op. at., p. 33: "il est important de marquer les differens degrés de la necessité, et de voir qu'il y en a qui ne sauroient nuire, comme il y en a d'autres qui ne sauroient estre admis sans donner lieu à de mauvaises consequences".

3 Cf. op. cit., III, § 367, pp. 332-333.

${ }^{4}$ Assim, por exemplo, ao longo da Teodiceia, Leibniz opera simultânea e sistematicamente com a identificação entre contingência e não necessidade (cf., LEIBN IZ, 1996b, p. 296) e com a tese de que há formas de necessidade que não se opõem à contingência e à liberdade (cf. op. at., p. 37).

5 Trata-se de uma exigência suficiente: Leibniz chega inclusivamente a afirmar que o próprio Spinoza seria obrigado a reconhecer que nem tudo é absolutamente necessário, posto que admite uma dupla definição do impossível: "Impossibile est aliquid vel quia ejus definitio contradictionem involvit, quia vel nulla causa datur ad producendam rem talem determinata" (C f. A d sententiam Spinoz ae de necessitate rerum - in: LEIBN IZ, 1980, IV, p. 1777). Com efeito, embora se defina sempre como aquilo cujo oposto é impossivel ou implica contradição, a multiplicidade de sentidos do imposśvel, aqui explicitamente reconhecida por Spinoza, obriga a distinguir formas de necessidade, e, por isso, a rever e a negar as teses necessitaristas.

${ }^{6}$ Cf. LEIBN IZ, 1996b, p. 29.

${ }^{7}$ Cf. D ialogue effectif sur la liberté de l'homme et sur l'origine du mal, in: LEIBN IZ, 1998, p. 362.

8 Cf. Extrait de B ellarmin. in: LEIBN IZ, 1998, p. 297.

${ }^{9}$ Cf. R eflexions sur B ellarmin, in: LEIBN IZ, 1998, p. 306.

10 Cf. LEIBN IZ, 1996b, pp. 411-412.

11 Cf. LEIBN IZ, 1996b, p. 390.

12 Ibidem : "M. Hobbes ne veut pas non plus entendre parler d'une nécessité morale, parce qu'en effet tout arrive par des causes physiques. $M$ ais on a raison cependat de faire une grande 
différence entre la necessité qu'oblige le sage á bien faire, qu'on appelle morale, et qui a lieu même par rapport à D ieu, et entre cette necessité aveugle, par laquelle Epicure, Straton, Spinoza et peutestre M. H obbes ont crû que les choses existoient sans intelligence et sans choix, et par consequent sans D ieu".

13 Ibidem: "cette necessité est absolue, parce que tout ce qu'elle porte avec elle doit arriver, quoy'on fasse".

${ }^{14}$ Cf. LEIBN IZ, 1996b, p. 33.

15 Cf. A M agnusW edderkopf (1671) in: LEIBN IZ, 1926, I, p. 117: rei necessitatem = attendendi utilitatem. Cf. tb. SurT homasius, U trum haeresis sit crimen, in: LEIBN IZ, 1998, p. 211: Leibniz refere-se ao que chama "necessidade de meio absoluta", indicando com isso que algo é absolutamente indispensável para um fim sem ser em si mesmo absolutamente necessário.

$16 \mathrm{~N}$ outros textos Leibniz apresenta a especificidade desta noção do necessário indicando que as outras formas de necessidade incluem uma reduplicação, muitas vezes elidida por comodidade, e que os homens costumam omitir para não dizer duas vezes a mesma coisa. Cf. C onfessio P hilosophi, in: LEIBN IZ, 1980, III, p. 128.

17 LEIBN IZ, 1996b, p. 386: "Q uoyque sa volonté soit toujours immanquable, et aille toujours au meilleur, le mal ou le moindre bien, qu'il rebute, ne laisse pas d'être possible en soy; autrement la necessité du bien seroit geometrique (pour ainsi dire) et metaphysique, et tout à fait absolue; la contingence des choses seroit detruite, et il n'y auroit point de choix. M ais cette maniere de necessité, qui ne detruit point la possibilité du contraire, n'a ce nom que par anal ogie; elle devient effective, non pas par la seule essence des choses, mais par ce qui est hors d'elles, et au dessus d'elles, savoir par la colonté de D ieu. Cette necessité est appelée morale, parce que chez le sage, necessaire et dû sont des choses equivalentes".

18 Cf. LEIBN IZ, 1996b, p. 393: "la necessité de la consequence n'empêche point que l'evenement ou le consequent ne soit contingent en soy".

19 | bidem : «que Dieu prevoye qu'un evenement arrivera, il n'est necessaire qu'il arrive ».

20 l bidem.

21 Cf. LEIBN IZ, 1996b, p. 50.

22 Ibidem: "les verités de la R aison sont de deux sortes; les unes sont ce qu'on appelle les Verités E ternelles, qui sont absolument necessaires, en sorte que l'opposé implique contradiction; et telles sont lesVerités, dont la necessité est logique, metaphysique, geometrique, qu'on ne sauroit nier sans pouvoir estre mené à des absurdités. II y en a d'autres qu'on peut appeller Positives, parce qu'elles sont les loix qu'il a plû à Dieu de donner à la nature, ou qu'elles en dependent. $\mathrm{N}$ ous les apprenons, ou par l'experience, c'est à dire a posteriori, ou par la raison, et a priori, c'est à dire par des raisons de la convenance, qui les ont fait choisir. Cette convenance a aussi ses regles et raisons, mais c'est le choix libre de Dieu, et non pas une necessité Geometrique, qui fait preferer le convenable et le porte à l'existence. Ainsi on peut dire, que la necessité physique est fondée sur la necessité morale, c'est à dire sur le choix du sage, digne de sa sagesse; et que l'une aussi bien que l'autre doit estre distinguée de la necessité geometrique".

23 Cf. LEIBN IZ, 1996b, pp. 49 e 64.

doispontos, Curitiba, São C arlos, vol. 2, n. 1, p.53-82, outubro, 2005 
24 Cf. LEIBN IZ, 1996b, p. 51.

25 Cf. LEIBN IZ, 1996b , pp. 51-2.

${ }^{26}$ Cf. LEIBN IZ, 1996b, p. 64: "La distinction qu'on a coutume de faire entre ce qui est au dessus de la raison et cequi est contre la raison s'accorde assés avec la distinction qu'on vient de faire entre les deux especes de la necessité". As duas espécies de necessidade mencionadas são a necessidade metafísica e a necessidade física (cf. id., § 20, p. 62)

27 C f. LEIBN IZ, 1996b, p. 52.

28 Cf. LEIBNIZ, 1996b, p. 62: Leibniz refere-se "aux verités, dont la necessité est appelée L ogique ou M etaphysique, c'est à dire, dont l'opposé implique contradiction".

29 M etafísica, 1015 a 33-36 (AR IST ÓT ELES, 1998, pp. 232-3).

30 Cf. LEIBN IZ, 1996b, p. 393.

31 Cf. D e religione magnorum virorum. in: LEIBN IZ, 1998, p. 37.

32 Cf. LEIBN IZ, 1996b, p. 35.

33 Cf. LEIBN IZ, 1988, p. 498: "C ogere est necessariam alicujus actionem facere" ; Id., 499: "Imperare est significare T ibi, nos velle, ut sit impositaT ibi necessitas faciendi".

\section{Referências bibliográficas}

AR IST Ó TELES. 1998. M etafísica de A ristóteles. Ed.V. G.Yebra. 2ª ed. $M$ adri: Editorial Gredos.

LEIBN IZ, G. 1996a. D ie philosophischen Schriften. Ed. C. I. G erhardt. Vol. I-VII. H ildesheim: G eorg O ImsVerlag.

LEIBN IZ, G. 1996b. E ssais deT héodicée sur la bonté de D ieu, la liberté de I'homme et l'origine du mal. In: G . W. L eibniz - D ie philosophischen Schriften. Ed. C. I. Gerhardt. V.VI. H ildesheim: G eorg O ImsVerlag.

LEIBN IZ, G. 1926. G ottfried W ilhelm L eibniz: Sämtliche Schriften und B riefe - Philosophischer B riefwechsel (1663-1685). S II. Ed.Prussischen A kademie der W issenschaften. D armstadt: $O$ tto $R$ eichl Verlag.

LEIBN IZ, G. 1980. G ottfried W ilhelm L eibniz: Sämtliche Schriften und B riefe - Philosophische Schriften (1672-1676). SVI. Ed. A kademie der W issenschaften der DDR . Berlin: A kademie Verlag. 


\section{2}

LEIBN IZ, G. 1998. L eibniz: Textes inédits d'après les manuscrits de la Bibliothèque provinciale de H anovre. Ed. G. G rua.V. I-II. 2ª ed. Paris: PU F.

LEIBN IZ, G. 1988. 0 pusaules et fragments inédits de L eibniz extraits des manuscrits de la B ibliothèque $\mathrm{R}$ oyale de $\mathrm{H}$ anovre. $\mathrm{Ed}$. L. Couturat. Hildesheim. G eorg O ImsVerlag. 